Vol.1 No.1, Spring 2020

\title{
Relationship between health literacy and general health among patients with leukemia before bone marrow transplant
}

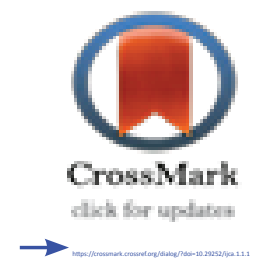

Jalali $\mathrm{M}^{1}$, khodabakhshi koolaee $\mathrm{A}^{2^{*}}$

1- M.Sc. in Counseling, Department of Counseling, Science and Research Branch, Islamic Azad University, Tehran, Iran.

2- Assistant Professor, Department of Psychology and Education Science, Faculty of Humanities, Khatam University, Tehran, Iran.

Corresponding Author: khodabakhshi koolaee A, Assistant Professor, Department of Psychology and Education Science, Faculty of Humanities, Khatam University, Tehran, Iran.

Email: a.khodabakhshid@khatam.ac.ir

Received: 25 March 2019

Accepted: 30 April 2019

\begin{abstract}
Introduction: Health literacy is one of the crucial factors that has a considerable influence on health. However, the previous studies indicated that leukemia decrease the level of health. Therefore, the aim of current study is to investigate the relationship between health literacy and general health among patients with leukemia before bone marrow transplant.
\end{abstract}

Method: This research is a descriptive and correlational research. The sample of current research included 100 patients with leukemia hospitalized into Shariati Hospital in Tehran that were selected through convenience simple in 2015. They responded to two research instruments such as; Health Literacy for Iranian Adults (HELIA) and Goldberg's General Health Questionnaire. Data was analyzed by utilizing the Pearson correlation and regression step by step.

Results: The findings of Pierson test indicated that there was a significant positive relationship between health literacy and general health $(\mathrm{sig}=0.01)$. In addition, based the results of regression, health literacy could be predicted the general health in patients with leukemia ( $\operatorname{sig}=0.001)$.

Conclusion: The results emphasize on the relationship between health literacy and general health among patients with leukemia. Thus, it is suggested that this result can be considered in prevention programs (primary and secondary) in order to increase the patient health.

Keywords: Health Literacy, Health, Leukemia.

\begin{tabular}{|l|l|}
\hline \multicolumn{3}{|c|}{ Access this article online } \\
\hline & Website: \\
\hline www.ijca.ir
\end{tabular}




\section{رابطه سواد سلامتى با سلامت عمومى در بيمار ان مبتلا به سرطان خون قبل از عمل ييوند مغز استخوان}

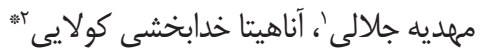

1- أ كارشناس ارشد مشاوره، كروه مشاوره، واحد علوم و تحقيقات، دانشكاه آزاد اسلامى، تهران، ايران.

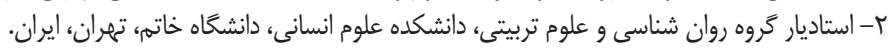

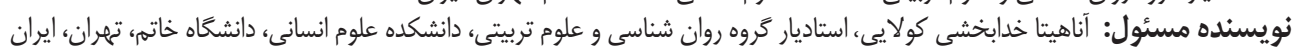

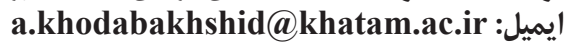

مقدمه: سواد سلامتى يكى از مهمترين عواملى است كه نقش بسزايى در سلامت افراد دارد. اين در حالى است كه تحقيقات ييشين نشان

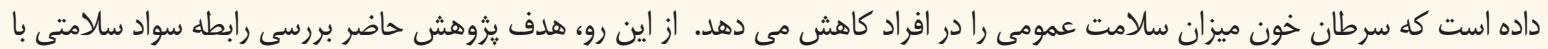

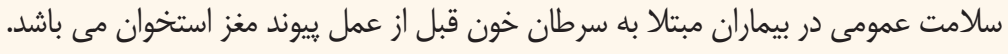

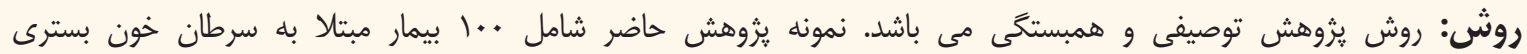

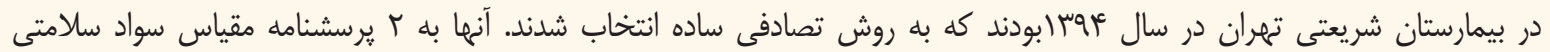
و سلامت عمومى Goldenberg ياسخ دادند. داده ها با استفاده از همبستخى يبرسون و رگر سيون كام به كام، مورد تجزيه و تحليل قرار ترفت. يافته ها: نتايج آزمون آمارى همبستخى ييرسون نشان داد رابطه معنادار مثبتى بين سلامت عمومى و سواد سلامتى در بيماران مبتالا به

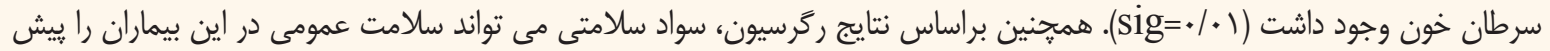

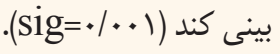

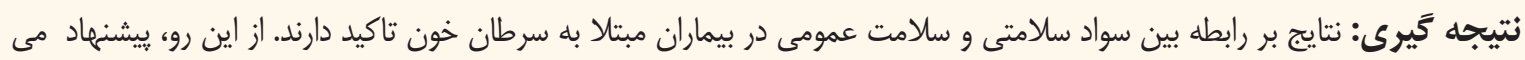

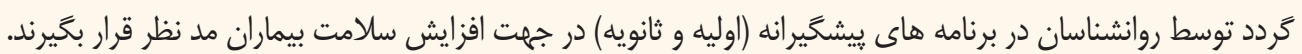
كليد وازه ها: سواد سلامتى، سلامت، سرطان خون. 


\section{مهديه جلالى و همكاران}

از داشتن توانايى صرف در خواندن، نوشتن و يا فهميدن اعدادو شماره ها در مكان هاى بهداشتى درمانى است. سواد سلامت در دراف

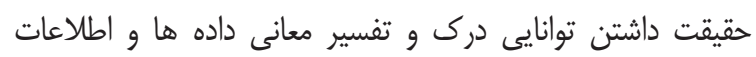

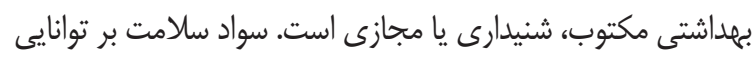

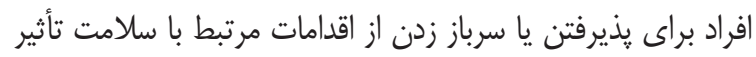

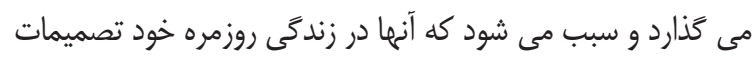

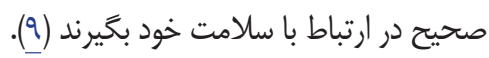

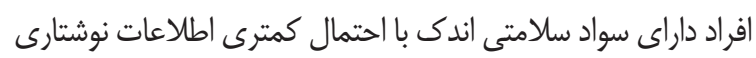
و كَتارى ارايه شده توسط متخصصان سلامتى رادرك و به دستورات

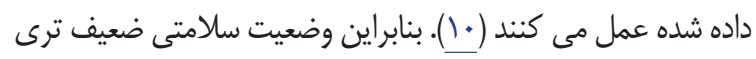
دارند ميزان بسترى شدن و مراجعه به يزشك در آنها بيشتر است، در ممهارتهاى خود مراقبتى ضعيف عمل مى كنند، مراقبت ييشخيرانه كمترى دارند و در نتيجه هزينه هاى يزشكى بيشترى را متحمل مى

تحقيقات بيشين نشان داده است سواد سلامتى محدود با سلامت

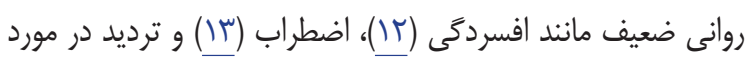
تصميم گَيرى در درمان بيمارى هاى ييشرونده (بار) رابطه دارد.

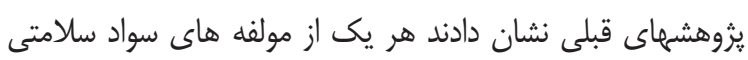

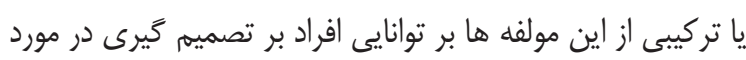

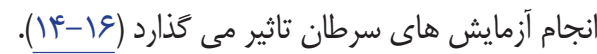

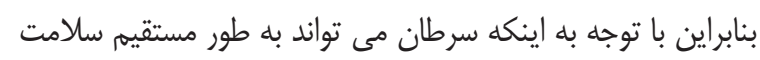

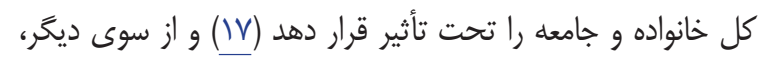
يزوهش در خصوص سواد سلامتى و سلامت عمومى بيماران، مى دى تواند به كشف و شناسايى راههايى منجر شود كه به وسيله آن بتوان

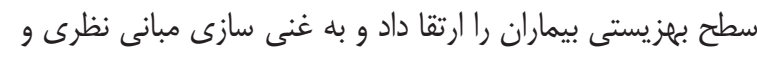

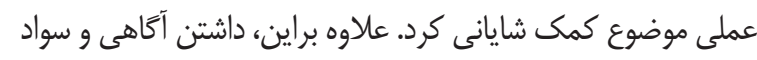

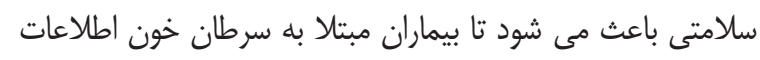

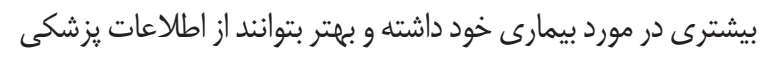

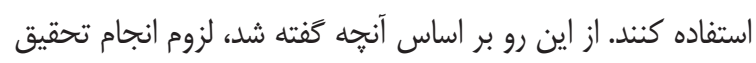

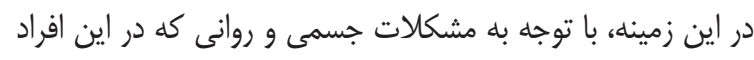

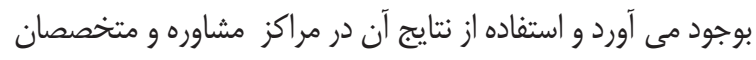

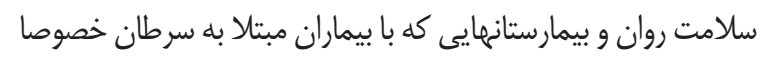

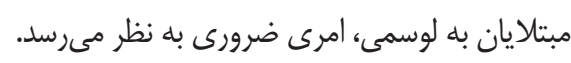

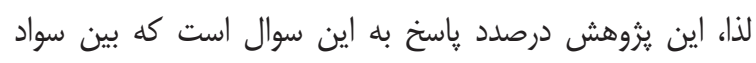

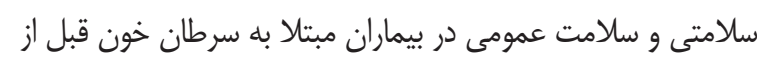
عمل يبيوند مغز استخوان خه رابطهى وجود دارد؟

\section{مقلدمه}

سرطان مى تواند اختلالات روانى و اجتماعى مختلفى در زندگى

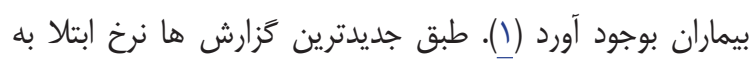
سرطان خون در ايران افزايش يافته است. به نحوى كه ميزان بروز

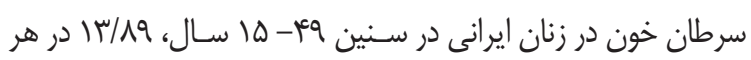

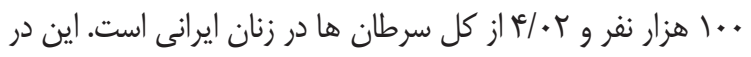

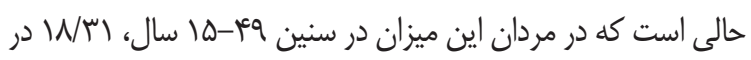

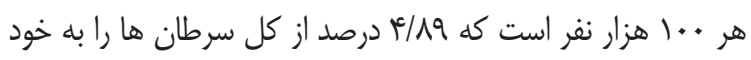

اختصاص داده است (r) - (ب).

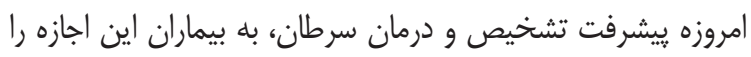

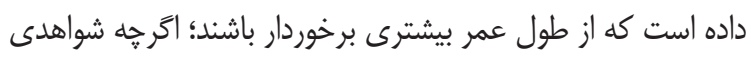

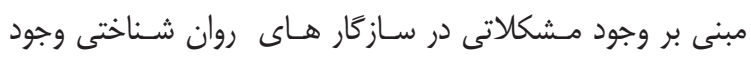

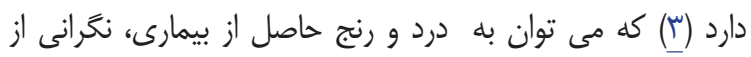

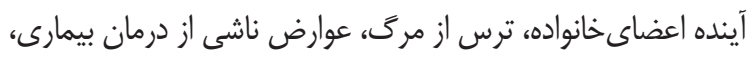
كاهش ميزان عملكردها اختلال در تصوير ذهنى و مشكالات جنسى اشاره كرد كه همخى از جمله عواملى هستند كه سلامت عممومى بيمار

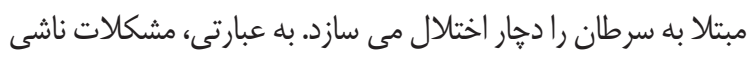
از اين بيمارى بلهتصويرذهنى و سلامت عمومى فرد آسيب مى رساند مئد

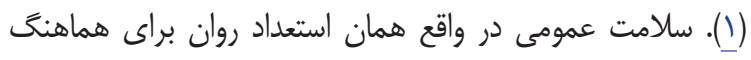

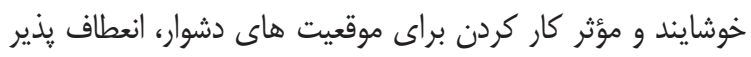
بودن و توانائى داشتن براى بازيابى تعادل خود است كه سازمان جهانى بهداشت آن را درون مفهوم كلى بهداشت جاى داده است (مآ).

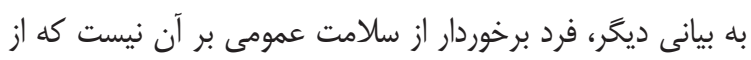

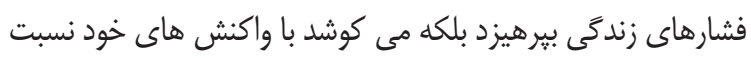

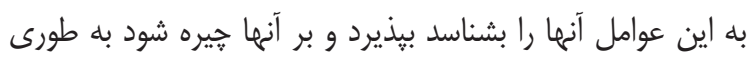

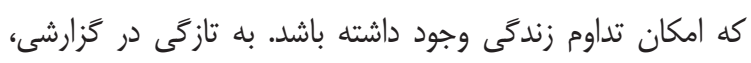
سواد سلامت (Health Literacy) به عنوان يكى از بزر گترين تعيين

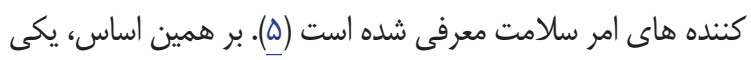
از عوامل مهرم در سلامتعمومى بيماران مبتلا به سرطان از جمله سرطان خون سواد سلامتى است (ع).

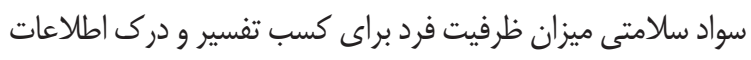

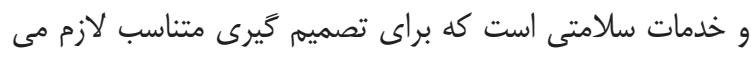
باشد (V). سواد سلامتى شامل مهارتهاى خواندن، شنيدن، تجزيه و

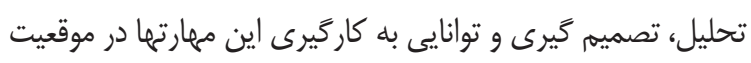

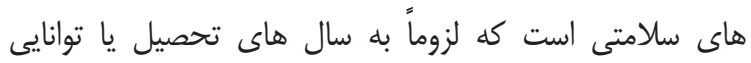
خواندن عمومى برنمى گردد (ي).. به عبارتى ديگر سواد سلامت فراتر 
براى اندازه كيرى سلامت عمومى از يرسشنامه 1 إعبارتى سلامت عمومى كلدبرى (Goldberg Health Questionnaire) استفاده شد كه يك يرسشنامه غربالكَّى مبتنى بر خود گَزارش دهى است.

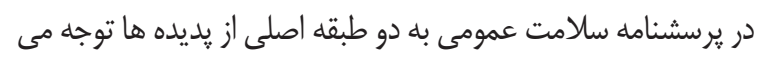

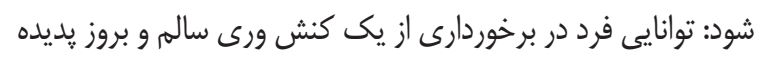

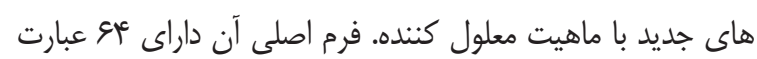

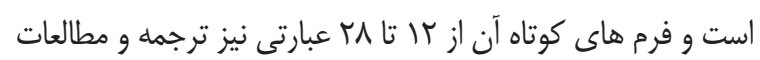

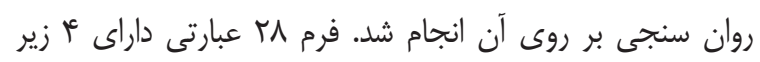

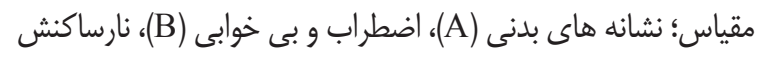

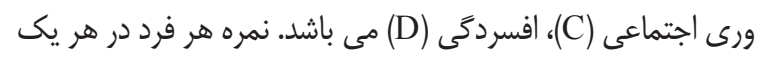

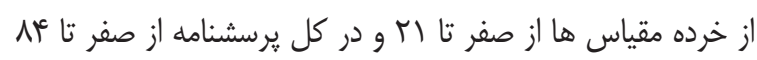

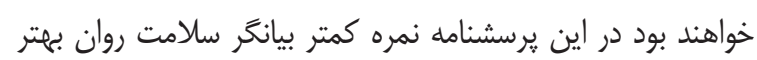

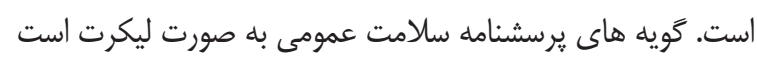

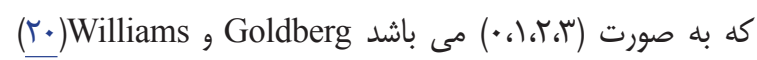

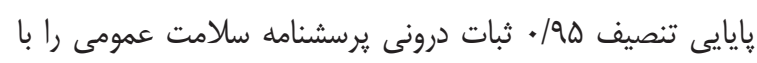

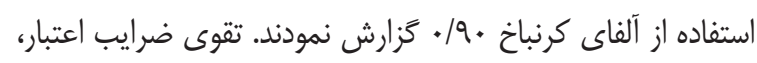

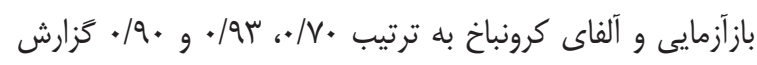

در نهايت، داده ها با استفاده از آزمون همبستخى يبرسون، تحليل

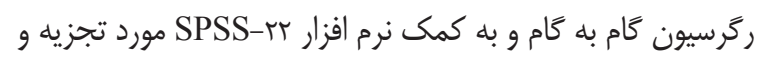

تحليل قرار گرفت.

\section{يافته ها}

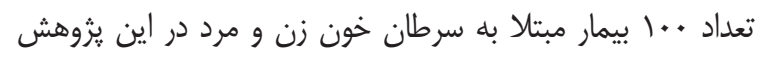

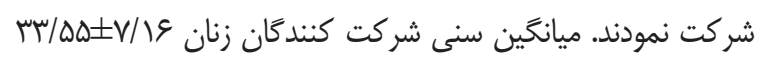

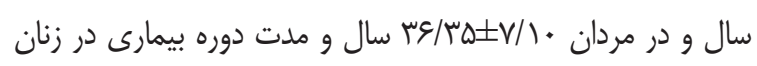
F F
روش مطالعه

روش يزوهش توصيفى از نوع همبستخى مى باشد. لذا جامعه آمارى

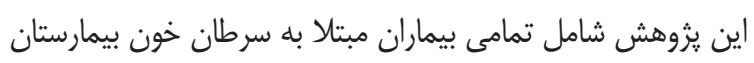

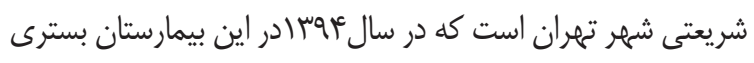

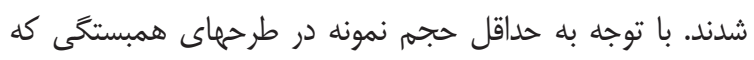

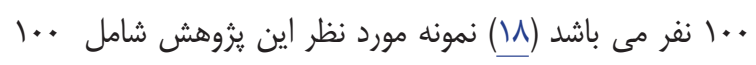

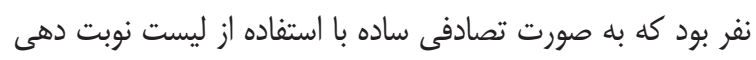

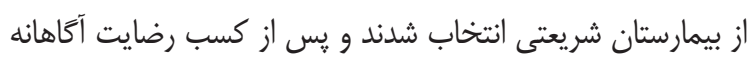
از آزمودنيها يرسشنامههاى سلامت عمومى و سواد سلامتى بين آنها

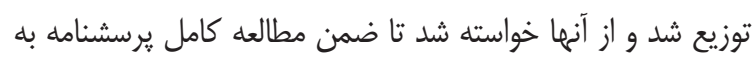
تمامى سوالات آنها ياسخ دهند. جهت رعايت اصول اخلاقى يس از اخذ رضايت آكاهانه از بيماران،

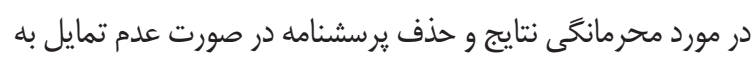
همكارى، به بيماران اطمينان داده شد.

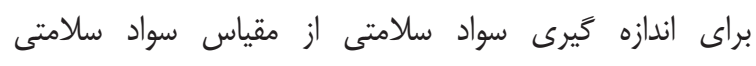
(HELIA) (Health Literacy for Iranian Adults) اين ابزار توسط منتظرى و همكاران ساخته شده كه داراى سـ سوال

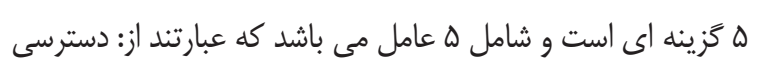

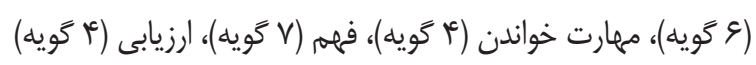
و تصميم گيرى و كاربرد اطلاعات سلامت (זاتويه). روايى سازه اين مقياس با استفاده از روش تحليل عاملى اكتشافى و يايايى آن با باليا

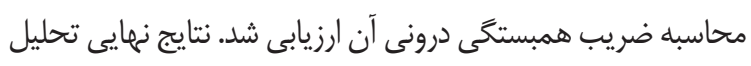

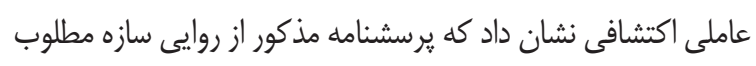

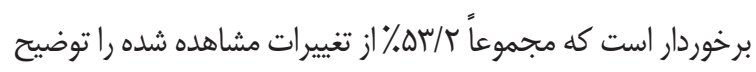

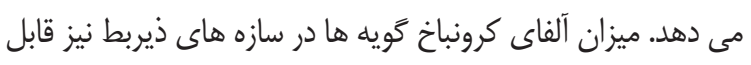

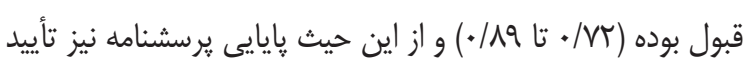

شده است (19).

جدول (: مشخصات جمعيت شناختى بيماران

\begin{tabular}{|c|c|c|c|c|c|}
\hline \multicolumn{2}{|c|}{ زن } & \multicolumn{2}{|c|}{ مرد } & \multirow{2}{*}{\multicolumn{2}{|c|}{ متغير }} \\
\hline فراوانى & درصد & فراوانى & درصد & & \\
\hline IT & IT & $v$ & V & سيكل & \\
\hline rT & Tr & TF & rF & دييلم & تحصيلات \\
\hline 19 & 18 & 9 & 9 & فوق دييلم & \\
\hline Mr & mf & - & - & خانه دار & \\
\hline if & if & Mf & Mf & كارمند & \\
\hline$r$ & $r$ & v & v & آزاد & شغل \\
\hline- & - & 9 & 9 & كارگر & \\
\hline
\end{tabular}

نتايج همبستخى ييرسون، بين سواد سلامتى و سلامت عمومى با استفاده از آزمون يك دامنه براى كل آزمودنىها در (جدول r) نشان 


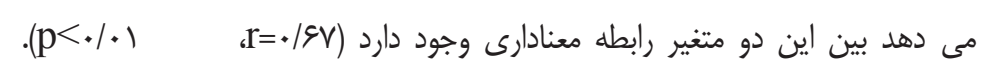

جدول ז: ضرايب همبستى ساده بين متغير ييش بين (سواد سلامتى)، و متغير ملاك (سلامت عمومى)، در كل آزمودنى ها

متغير ملاكى 1 سواد سلامتى

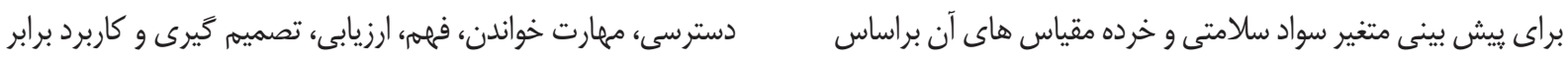

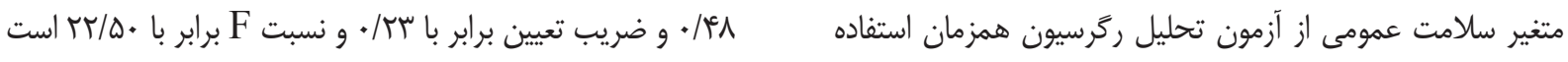

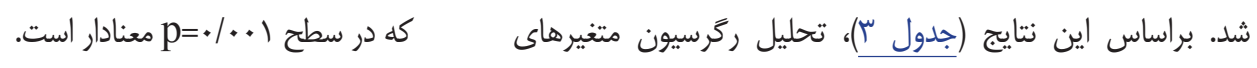
جدول ب: نتايج تحليل ركَرسيون كام به كَام: ييش بينى سلامت عمومى بر اساس سواد سلامتى

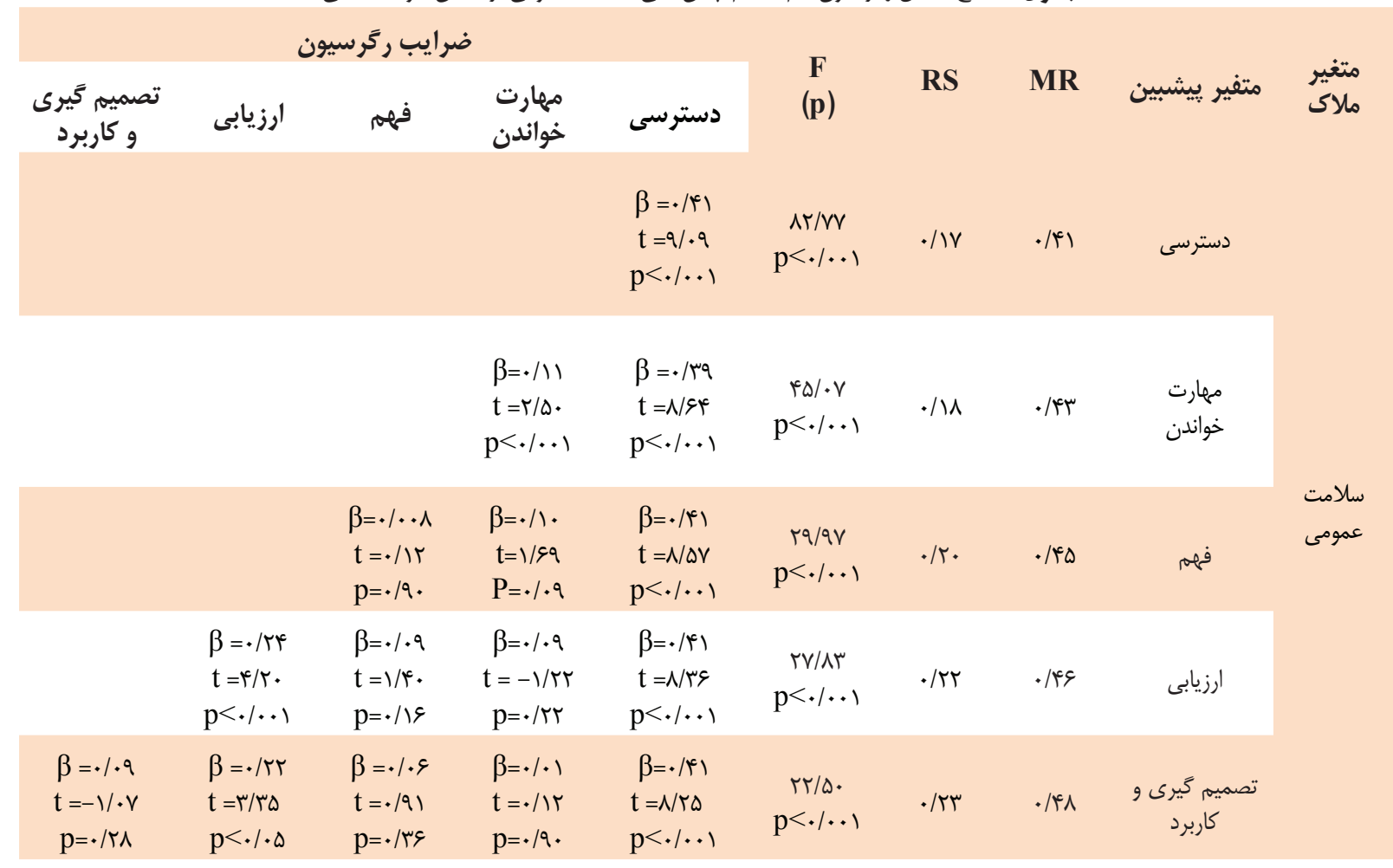

سلامتى مناسب، شانس دريافت درمان شيمى درمانى را در بيماران

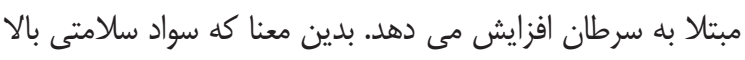

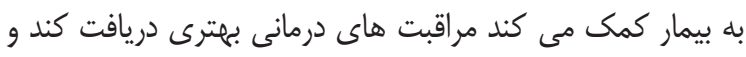

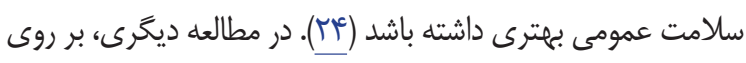

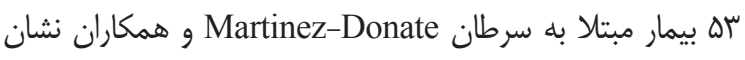
دادند سطوح بالاتر سواد سلامتى موجب بهبود مراقبت شده است و و

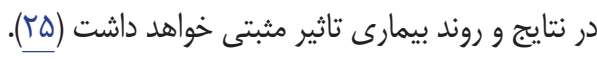
همجنين، يافته هاى اين تحقيق نشان داد سواد سلامتى و خرده

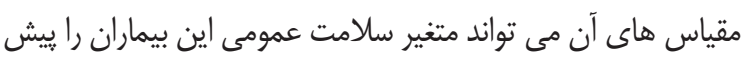

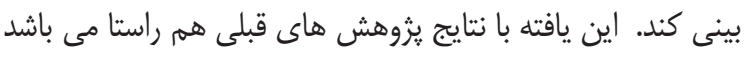

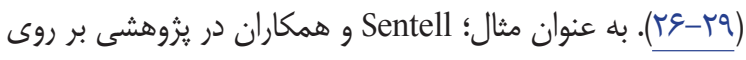

يزوهش حاضر به منظور تعيين رابطه بين سواد سلامتى با سلامت

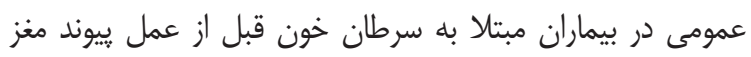

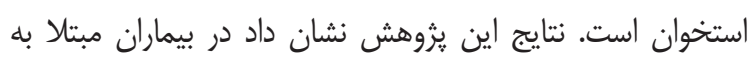

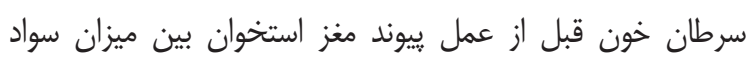

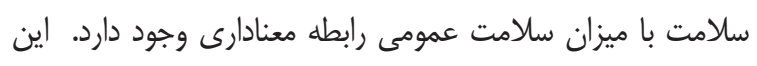

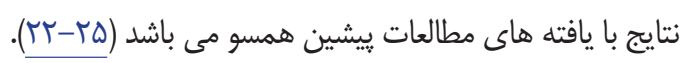
Halverson

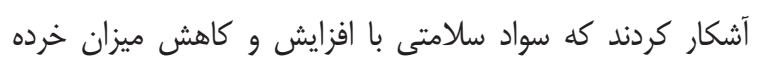
مقياس هاى سلامت فيزيكى، كاركردى، عاطفى، بهزيستى روانى

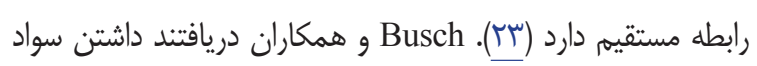


افزايش سلامت عمومى اين بيماران دارد (ع). بديهى است از آنجا كه يُوهش حاضر بر روى بيماران مبتلا بهان بيمارى سرطان خون در بيمارستان شريعتى شهر تهران انجام شده

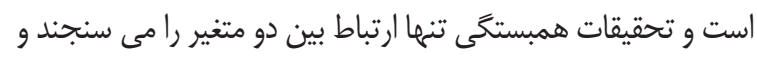
نمى توان با قطعيت در مورد رابطه علت و معلولى آنها صحبت كرد،

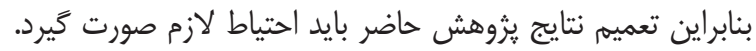

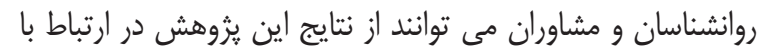

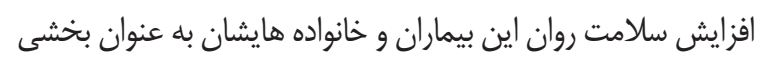
از سلامت عمومى آنان مورد استفاده قرار دهند.

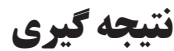

با تكيه بر يافته هاى بزوهش حاضر مبنى بر تاثير سواد سلامنى بر

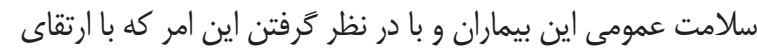

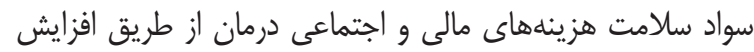

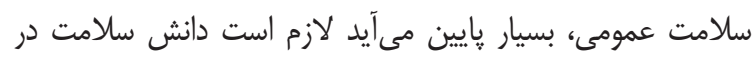
زمينه ييشَّيرى درمان و طى دوره درمان از طريق رسانه هاى جمعى باليق و همجنين كار كاه هاى آموزشى به اين بيمار ان ارائه شود.

\section{تشكر و قدردانى}

اين مقاله برَّرفته از بِايان نامه كارشناسى ارشد رشته مشاوره نويسنده

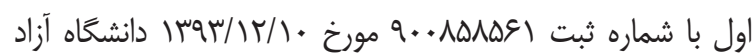
اسلامى واحد علوم و تحقيقات تهران مى باشد. نويسندكان مقاله

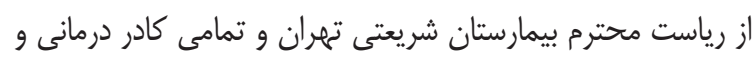
همجنين بيمارانى كه در انجام اين تحقيق همكارى كردند تشكر و

$$
\text { قدردانى مى كنند. }
$$

\section{References}

1. Fallah R, Golzar M, Dastani M, et al. Effectiveness of Spiritual Intervention on Increasing Hope and Mental Health of Women Suffering from Breast Cancer. Thought and Behavior in Clinical Psychology 2011;5(19):65-76. [in Persian]

2. Holzner B, Kemmler G, Kopp M, et al. Quality of life of patients with chronic lymphocytic leukemia: results of a longitudinal investigation over 1 yr. Eur J Haematol 2004; 72: 381-389.

3. Ferrario C, Cosentino D, Lines $\mathrm{H}$, et al. Factors influencing the length of stay for breast cancer patients undergoing mastectomy: An independent sector perspective. Eur J Surg Oncol 2016;5(42):23.
نقش ييش بينى كننده سلامت عمومى در ميزان مشاركت افراد در غربالكَرى سرطان سينه و َّردن رحم نشان دادند امريكايى هاى

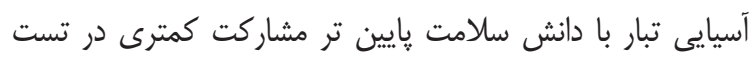

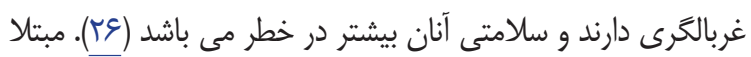
به سرطان سينه، Sarkar و همكاران نقش ييش بينى كننده سواد

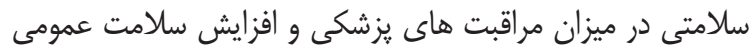
و رضايت بيشتر از درمان هاى دريافتى در ميان جوامع اسيانيايى دايى

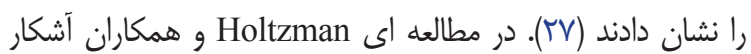
كردند ميزان سواد سلامتى مى تواند ميزان عدم مراجعه بيماران به

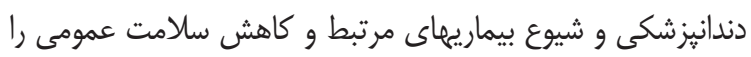

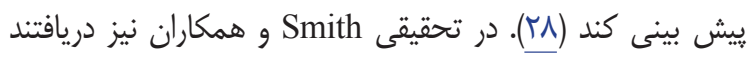

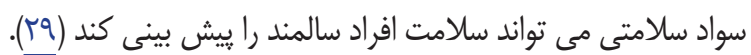
در تبيين اين يافته ها مى توان كفت، از آنجا كه سواد سلامتى شامل

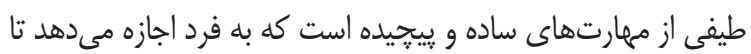
در تصميمَّيرىهاى درمانى مشاركت داشته باشد از اين رو، موجب ترغيب فرد بيمار به دريافت اطلاعات بيشتر و جستجوى درمان مى دي دران شود. به عبارتى سواد سلامتى يايين منجر به كوتاه شدن مدت اقامت بيماران در بيمارستان شده كه اين امر به نوبه خود سبب كاهش بانس هزينه ها و به عبارت ديخر جلوكيرى از هدررفتن بخشى از بودجه بخش سلامت مى شود (+r). از سوى ديخر، سواد سلامتى بالا از طريق رعايت رزيم غذايى سالم و

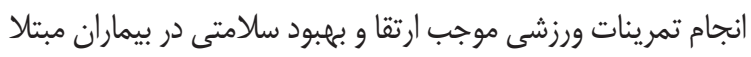

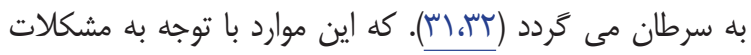
جسمانى اين بيماران به دليل عوارض مربوط به خود بيمـارى،

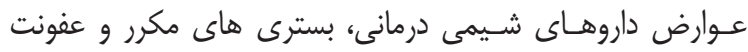

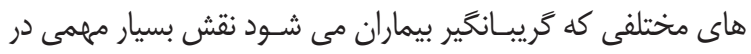

4. Norouzinia R, Aghabarari M, Kohan M, et al. Health promotion behaviors and its correlation with anxiety and some students' demographic factors of Alborz University of Medical Sciences. Journal of Health Promotion Management 2013;2(4):39-49.

5. Sørensen K, Van den Broucke S, Fullam J, et al. Health literacy and public health: a systematic review and integration of definitions and models. BMC public health 2012; 12(1): 80 .

6. Hadi N, Namvar E, Montazeri A. Health-related quality of life in adults leukemic patients. Payesh 2011;10(2):151-156. [in Persian]

7. Oldach BR, Katz ML. Health literacy and cancer screening: a systematic review. Patient education 
and counseling 2014;94(2):149-157.

8. van der Heide I, Uiters E, Schuit AJ, et al. Health literacy and informed decision making regarding colorectal cancer screening: a systematic review. The European Journal of Public Health 2015;25(4):575-582.

9. UNESCO: Literacy for all. Education for All Global Monitoring Report 2006. UNESCO Publishing; 2005.

10. Batterham RW, Hawkins M, Collins PA, et al. Health literacy: applying current concepts to improve health services and reduce health inequalities. Public health 2016;132:3-12.

11. McNaughton CD, Kripalani S, Cawthon C, et al. The association between health literacy and 90-day re-hospitalization or death: A cohort study of patients hospitalized for heart failure. Circulation: Cardiovascular Quality and Outcomes 2014;7(Suppl 1):127-127.

12. Loureiro LM, Jorm AF, Mendes AC, et al. Mental health literacy about depression: a survey of portuguese youth. BMC psychiatry 2013;13(1):1.

13. Furnham A. Mental health literacy and the anxiety disorders. Health 2013;5(03):521-531.

14. Sudore RL, Schillinger D, Knight SJ, et al. Uncertainty about advance care planning treatment preferences among diverse older adults. J Health Commun 2010;15(S2):159-171.

15. Berkman ND, Sheridan SL, Donahue KE, et al. Health literacy interventions and outcomes: an updated systematic review. Evid Rep Technol Assess 2011;1-941.

16. Oldach BR, Katz ML. Health literacy and cancer screening: a systematic review. Patient education and counseling 2014;94(2):149-157.

17. Wadhwa D, Burman D, Swami N, et al. Quality of life and mental health in caregivers of outpatients with advanced cancer. PsychoOncology 2013;22(2):403-410.

18. Delavar A. Applied Probability and Statistics in Psychology and Educational Sciences. 1th ed. Tehran: Roshd, 2014 [in Persian].

19. Montazeri A, Tavousi M, Rakhshani F, et al. Health Literacy for Iranian Adults (HELIA): development and psychometric properties 2014:13(5)589-599 [in Persian]

20. Goldberg DP, Williams P. A user's guide to the General Health Questionnaire. Windsor UK:
NFER-Nelson; 1988.

21. Taghavi M. Investigation of reliability and validity of general health questionnaire. Journal of Psychology 2002; 5(4): 381-398. [in Persian]

22. Al Sayah F, Williams B, Pederson JL, Majumdar SR, Johnson JA. Health literacy and nurses' communication with type 2 diabetes patients in primary care settings. Nursing research. 2014 Nov 1;63(6):408-17. 